\title{
PRECIPITAÇÃO NA AMÉRICA DO SUL - DADOS OBTIDOS EM ESTAÇõES METEOROLÓGICAS AUTOMÁTICAS E SISTEMAS ORBITAIS
}

\author{
SILVA, Carlos Batista - krlosbatist@gmail.com \\ Universidade de São Paulo / USP \\ SILVA, Maria Elisa Siqueira - elisasiq@usp.br \\ Universidade de São Paulo / USP \\ AMBRIZZI, Tércio - tercio.ambrizzi@iag.usp.br \\ Universidade de São Paulo / USP
}

TOMMASELLI, José Tadeu Garcia - tadeutommaselli@gmail.com Universidade Estadual Paulista / UNESP - Presidente Prudente

\author{
PATUCCI, Natália Nunes - natalia.oliver@usp.br \\ Universidade de São Paulo / USP
}

MATAVELI, Guilherme Augusto Verola - guilhermemataveli@gmail.com Universidade de São Paulo / USP
LIMA, Bruna Simões - bruna.simoes.lima@usp.br Universidade de São Paulo / USP
CORREA, Wesley Campos - wesley.campos.correa@gmail.com Universidade Federal do Espírito Santo / UFES

\begin{abstract}
RESUMO: O objetivo deste trabalho foi verificar a representatividade de dados de precipitação pluvial compilados para três fontes de dados globais com grades regulares com resoluções espaciais distintas, obtidos a partir de informações orbitais e dados observados localmente, e, a associação com as observações realizadas em estações meteorológicas automáticas, para o período de 01 de janeiro de 2008 a 31 de dezembro de 2015. Os dados de precipitação das estações automáticas foram obtidos da rede do Instituto Nacional de Meteorologia, INMET, para os municípios de Paranaponema e Joaquim Távora, no Paraná, Ourinhos e Presidente Prudente, em São Paulo. Os conjuntos de dados globais comparados aos dados das estações meteorológicas automáticas foram obtidos dos projetos CHIRPS, TRMM e GPCP, com resoluções espaciais de 0,05, 0,5 e 2,5 graus, respectivamente. Embora haja uma associação geral entre os padrões anual e sazonal dentre as três fontes de dados globais, a comparação com dados observados localmente mostra algumas discrepâncias. A correlação linear entre os dados diários de precipitação das estações meteorológicas automáticas, EMA, e dados globais em grades regulares apresentam valores menores do que 0,15 para todas as estações meteorológicas, com exceção da EMA de Presidente Prudente, SP, que apresenta valores do coeficiente de correlação linear maior que 0,53 . Os resultados das análises de correlação entre os dados diários das estações de Ourinhos, Paranaponema e Joaquim Távora, apesar de serem baixos apresentam significância estatística. Na escala pentadal, os valores de correlação linear entre os dados das EMA e os dados globais, CHIRPS, TRMM e GPCP, são maiores que 0,60. Os valores de correlação linear entre os dados das EMA e os dados globais, na escala mensal, são maiores que 0,48 . Tanto na escala pentadal quanto mensal, todos os valores do coeficiente de correlação linear apresentaram significância estatística para $p=0,05$. Os ajustes lineares para a precipitação mensal registrada na EMA de Presidente Prudente com base em dados globais apresentaram coeficientes de determinação iguais a $45 \%, 55 \%$ e $47 \%$ para
\end{abstract}


dados diários, pentadais, e mensais, respectivamente, indicando a viabilidade de se usar os dados globais do CHIRPS, TRMM e GPCP para a representação dos dados registrados diretamente nas estações meteorológicas automáticas

PALAVRAS-CHAVE: dados globais de precipitação; América do Sul; estações meteorológicas automáticas; validação de dados.

\title{
PRECIPITATION IN SOUTH AMERICA - DATA OBTAINED FROM AUTOMATIC
} METEOROLOGICAL STATIONS AND ORBITA SYSTEMS

\begin{abstract}
The aims this paper was to verify the validity of rainfall data compiled for three global datasets of regular grids with different spatial resolutions obtained from orbital information and locally observed data, and, the respective association with observations made in automatic meteorological stations, AMS, for the period from January 1, 2008 to December 31, 2015. The precipitation data of the automatic stations was obtained from the National Institute of Meteorology (INMET), for the municipalities of Paranaponema and Joaquim Távora, in the state of Paraná, Ourinhos and Presidente Prudente, in the state of São Paulo. The global datasets compared to the meteorological station data were obtained from the CHIRPS, TRMM and GPCP projects, with spatial resolutions of $0.05,0.5$ and 2.5 degrees, respectively. Although there is a general association between annual and seasonal patterns among the three sources of regular grid data considered, comparison with locally observed data shows some discrepancies. The linear correlation between daily precipitation automatic station data and global data in regular grids shows values lower than 0.15 for all meteorological stations, except for the Presidente Prudente automatic station, which presents linear correlation coefficient values greater than 0.53 . Results of correlation coeficients for daily data of Ourinhos, Paranaponema and Joaquim Távora stations, although low, are statistically significant. In the pentadal scale, the linear correlation values between the automatic station data and the global data, CHIRPS, TRMM and GPCP, are greater than 0.60. The linear correlation values between the automatic station data and the global data on the monthly scale are greater than 0.48. Both on the pentadal and monthly scales, all values of linear correlation coefficient presented statistical significance for $p=0.05$. Linear adjustments for monthly precipitation data in the Presidente Prudente AMS, based on global data, presented coefficients of determination equal to $45 \%, 55 \%$ and $47 \%$ for daily, pentadal and monthly data, respectively, indicating the possible use of CHIRPS, TRMM and GPCP values in the representation of local stations data.
\end{abstract}

KEYWORDS: global precipitation data; South America; automatic meteorological stations; data validation

\section{INTRODUÇÃO}

Os dados atmosféricos são atualmente provenientes de redes de estações meteorológicas (convencionais e automáticas) de superfície e altitude, além de serem obtidos por sensoriamento remoto. Há ainda as observações atmosféricas coletadas em boias oceânicas, navios e aviões. A importância de uma ampla rede de dados advém da busca pela compreensão do comportamento atmosférico em todas as escalas de sua ocorrência, desde a escala planetária até a escala local.

Os grandes volumes de dados meteorológicos abrangentes são logicamente importantes no escopo das ciências ambientais, pois permitem associar, direta ou indiretamente, os efeitos das condições atmosféricas em diferentes processos físicos e biológicos que redundam em alterações da superfície terrestre. Processos biológicos de desenvolvimento fenológico das plantas, a manutenção de ecossistemas, a produção de espaços agroprodutivos, e a organização dos espaços urbanos e rurais constituem exemplos de fatores 
da superfície terrestre que sofrem o impacto de condições hidrológicas. Observações pluviométricas e fluviométricas contribuem para compor o balanço hídrico de cada localidade.

As observações são tanto mais úteis quanto maior a resolução espacial com que são obtidas, de forma a melhor definir o fenômeno atmosférico e as propriedades superficiais intervenientes. A alta resolução constitui um fator importante devido à caracterização física mais precisa, e está associada também à característica não linear da atmosfera, que leva, em última instância, à alta variabilidade do fenômeno em todas as dimensões. Assim, a observação da atmosfera em alta resolução permite análises diagnósticas mais precisas e, certamente, previsões do tempo e clima com um grau maior de acerto.

Apesar da necessidade de uma base de dados meteorológicos consistente ser uma condição necessária para a realização de previsões e pesquisas científicas mais confiáveis, um dos grandes problemas relatados recorrentemente é a indisponibilidade de dados em áreas específicas. Embora, atualmente, a quantidade de observações atmosféricas seja bem maior do que em décadas anteriores (40-60 anos atrás), a falta de dados, sobretudo para o hemisfério sul, é ainda relatada como um dos grandes problemas para a compreensão do funcionamento da atmosfera (Arkin e Xie, 1994). Este aspecto constitui um dos motivos que justificou a realização, durante muito tempo, de estudos mais focados em áreas do hemisfério norte (Hoskins e Karoly, 1981). Os projetos de reanálise de dados obtidos com base em dados observados e modelagem numérica (Kalnay et al., 1996) surgiram, em grande medida, da necessidade de prover conjuntos consistentes de dados para todo o globo.

Na Geografia, as primeiras pesquisas voltadas à descrição de elementos do clima, como chuva e temperatura, também esbarraram, desde há muito, na limitação e disponibilidade de informações observadas, tal como apontam Morize (1906), Monteiro (1969) e Conti (1975). Mesmo depois de muitas décadas e da implementação de redes de observação, vários pesquisadores ainda identificam o problema da falta de dados (Cunha e Vechia, 2012 e Saviano, 2016). Os conjuntos de reanálises são usados, por exemplo, para estudos atmosféricos sobre regiões polares, onde a disponibilidade de dados é limitada (Bromwich et al., 2007). Os continentes sulamericano e africano são também exemplos de regiões com ausência acentuada de observações em vários setores.

Dentre as variáveis meteorológicas, a precipitação é uma das mais importantes em áreas tropicais e subtropicais para definir as condições climáticas locais (Arkin e Xie, 1994). Nos estudos geográficos, a importância da precipitação em regiões tropicais dá-se principalmente por sua alta variabilidade espacial e temporal e, portanto, pela ocorrência de eventos extremos episódicos que causam impactos socioambientais, no meio rural e urbano. Apesar de os modelos numéricos gerarem a variável precipitação em seus conjuntos de reanálise, a habilidade destes modelos em simular esta variável para o tempo presente apresenta muitas vezes erros maiores do que as estimativas da precipitação feita com base em dados observados localmente nas estações meteorológicas e dados advindos do sensoriamento remoto (Harada et al., 2017; Limberger et al., 2016). Assim, considerando-se a escassez de observação pluviométrica em muitas áreas do globo, particularmente no hemisfério sul, a comunidade científica tem gerado ao longo das últimas décadas conjuntos de dados globais de precipitação construídos a partir de 
dados coletados localmente e de informações oriundas do sensoriamento remoto, possibilitando então a realização de estudos mais confiáveis sobre as características espaciais e temporais desta variável. Tropical Rainfall Measuring Mission (TRMM) (Kummerow et al., 2000), Global Precipitation Climatology Project (GPCP) (Adler et al., 2003) e Climate Hazards Group Infrared Precipitation with Stations (CHIRPS) (Funk et al., 2015), Global Precipitation Climatology Centre (GPCC) e Climatic Research Unit Timeseries (CRU) (Harris, et al., 2013) são exemplos de conjuntos de dados de precipitação distribuídos em grades equispaçadas, gerados recentemente a partir de observações em estações meteorológicas e informações de sensoriamento remoto (Harris et al., 2013). A partir de 1979 os dados de sensoriamento remoto passaram a alimentar os modelos numéricos, fazendo com que a destreza deles aumentasse significativamente (Adler et al., 2003). De forma a caracterizar a possibilidade de uso de dados de precipitação obtidos a partir das fontes globais, propõe-se, neste estudo comparar a variabilidade espacial e temporal dos dados oriundos dos conjuntos globais TRMM, GPCP e CHIRPS para o domínio da América do Sul, além de comparar seus resultados a dados observados obtidos em quatro estações meteorológicas automáticas (EMA) da rede do Instituto Nacional de Meteorologia (INMET), localizadas nas regiões sul e sudeste do Brasil.

\section{DADOS E MÉTODOS}

A comparação dos dados de precipitação do TRMM, GPCP e CHIRPS com os dados observados nas estações meteorológicas automáticas do INMET foi realizada nas escalas diária, mensal e anual, para o período de 01 janeiro de 2008 a 31 dezembro de 2015. A seguir estão descritas as bases de dados usadas e os métodos estatísticos aplicados na comparação das séries temporais.

\subsection{DADOS DO TRMM, CPCP, CHIRPS E EMA}

O sistema de observação do TRMM é composto por três sensores principais: um radar de micro-ondas passivo para a detecção de precipitação (Precipitation Radar - PR), um radiômetro de micro-ondas passivo (TRMM Microwave Imager - TMI) e um radiômetro que opera na região espectral do infravermelho e do visível (Visible and Infrared Scanner - VIRS). Os dados do TRMM podem ser obtidos no endereço virtual http://pmm.nasa.gov/dataaccess/downloads/trmm e são fornecidos em uma matriz de dados igualmente espaçados com 0,25 graus de resolução espacial ( $28 \mathrm{~km}$, no equador). Os dados do TRMM estão disponíveis para o período de 1997 até o presente, a partir do estabelecimento de projeto conjunto entre pesquisadores dos Estados Unidos, Japão, França, Alemanha, Austrália, Israel e Tailândia para obtenção de dados de precipitação sobre a faixa tropical global, com informações entre 37o S e 370 N. Informações técnicas sobre os sensores que compõem o sistema TRMM são encontradas nos trabalhos de Simpson et al. (1988), Simpson (1996) e Kummerow (2000).

Os dados do projeto GPCP foram obtidos do site https://climatedataguide.ucar.edu/climate-data/gpcp-monthly-global-

precipitation-climatology-project; apresentam resolução espacial de 2,5 graus ( 278 km, no equador) e observações de 1979 até o presente. O GPCP foi criado a partir da união de três organismos internacionais: Organização 
Meteorológica Mundial (OMM), World Climate Research Program (WCRP) e Global Energy and Water Cycle Exchanges Project (GEWEX). O projeto foi lançando com o objetivo de minimizar a falta de dados globais de precipitação (Arkin e Xie, 1994). Estes autores argumentam que dados globais de precipitação auxiliariam a compreensão da distribuição da chuva na previsão de enchentes, produção de alimentos e controle de secas. O conjunto de dados do GPCP é formado com base na compilação de observações pluviométricas de mais de 6700 estações distribuídas pelo globo e estimativas de precipitação feitas com base em dados de satélites meteorológicos, GOES (Geostationary Operational Environmental Satellites, Estados Unidos), GSM (Geostationary Meteorological Satellite, Japão) e Meteosat (Meteorological Satellite, Comunidade Européia). As observações por satélite para a elaboração dos dados do GPCP representam a precipitação acumulada nos intervalos definidos pelos horários 0:00, 9:00 e 21:00 UTC.

Os dados do CHIRPS foram obtidos no endereço http://chg.geog.ucsb.edu/data/chirps/ e apresentam alta resolução espacial de $0,05^{\circ}$ graus (cerca de $5 \mathrm{~km}$, no equador), para séries de dados diários. 0 CHIRPS é uma base de dados de precipitação que cobre quase todo o globo, entre $500 \mathrm{~S}$ e $500 \mathrm{~N}$. Este conjunto de dados foi desenvolvido pelos pesquisadores da Universidade de Santa Bárbara (Califórnia, EUA) e do United States Geological Survey (USGS), com o objetivo de fornecer produtos quantitativos com alta resolução sobre as condições pluviais para monitoramento ambiental, visando melhorar as condições de previsibilidade de períodos de secas regionais de diversas partes do globo, garantindo, dessa forma, a identificação de áreas passíveis de insegurança alimentar (FEWSNET, Famine Early Warning Systems Network), sobretudo nas regiões mais desprovidas de recursos, como grande parte da África oriental. O produto elaborado pelo CHIRPS é alimentado por duas principais fontes: uma, constituída por estações meteorológicas (convencionais e automáticas) em mais de 27 mil pontos ao redor do globo, e outra, de dados obtidos por satélites meteorológicos. Antes de gerar o produto final do CHIRPS, os dados de estações de superfície são comparados com dados derivados das estimativas de precipitação por satélite (Funk et al., 2015). Os dados de estação de medições (séries mensais e pentadais) são combinados com dados de estimativas de precipitação obtidos de informações dos sistemas de satélites com alta resolução do GPCC (Becker, et al, 2011) e CRU (Harris, et al., 2013).

Os dados de estações meteorológicas automáticas no território brasileiro são encontrados no endereço virtual http://www.inmet.gov.br/sonabra/maps/pg_automaticas.php. As EMA são de fabricação finlandesa (marca Vaisala - MAWS 301) e, administradas pelo INMET. A estrutura física da estação automática é composta por sensores que medem variáveis meteorológicas (temperatura, umidade, pressão atmosférica, precipitação, direção e velocidade do vento e radiação solar), armazenando os dados em um banco de dados. A captação dos dados das variáveis meteorológicas é feita a cada minuto e, posteriormente, a informação é transmitida ao INMET. Antes de serem colocados à disposição para os diversos usos, os dados das EMA são validados com informações das estações meteorológicas convencionais do próprio INMET (INMET). A escolha das EMA usadas neste estudo foi realizada a partir de uma pré-comparação de seus dados com aqueles medidos por estações convencionais do INMET. A seleção 
das bases com dados de precipitação em grade, TRMM, CHIRPS e GPCP, baseou-se na resolução espacial dos diferentes conjuntos, os quais poderiam garantir maior adequação aos dados medidos pelas EMA.

\subsection{ANÁLISE ESTATÍSTICA}

A comparação entre os dados globais do TRMM, CHIRPS e GPCP e a validação com os dados de precipitação observada localmente nas EMA instaladas nos municípios de Ourinhos (SP), Presidente Prudente (SP), Paranaponema (PR) e Joaquim Távora (PR), localizados no extremo oeste paulista e norte do estado do Paraná, foram feitas para o período de 01 janeiro de 2008 a 31 dezembro de 2015. No decorrer do texto, as estações automáticas são denominadas de EMA-OURI, EMA-PPRU, EMA-JOTA e EMA-PARA. A localização de cada uma delas está indicada na Figura 1.

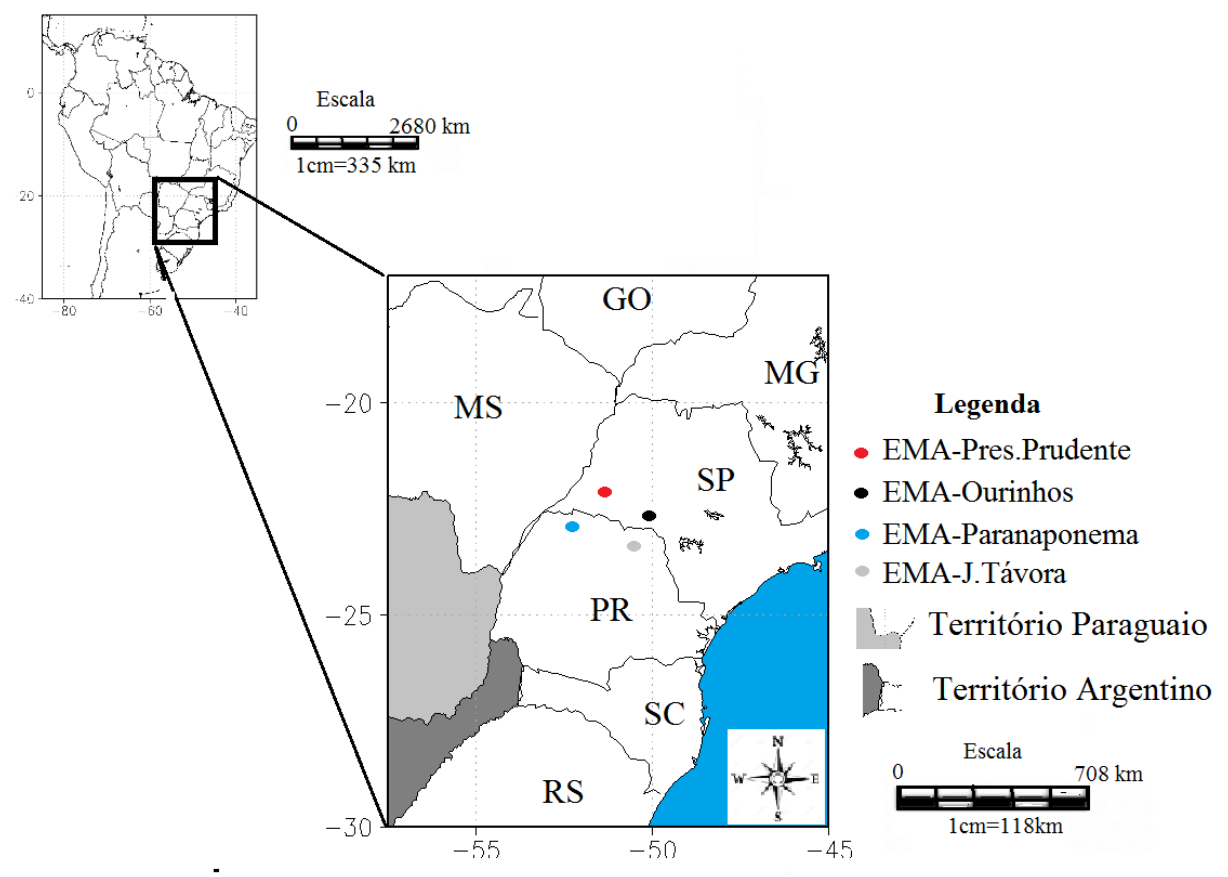

Figura 1 - Localização das estações meteorológicas automáticas do INMET no estado de São Paulo e Paraná.

As análises estatísticas aplicadas aos conjuntos de dados foram divididas em cinco etapas:

(i) Inicialmente, foi feita a comparação entre os dados globais dos projetos CHIRPS, TRMM e GPCP a partir de médias anuais e sazonais de precipitação, das séries com resolução mensal. O objetivo desta primeira etapa foi obter resultados que permitissem a discussão das semelhanças e diferenças espaciais da distribuição da precipitação sobre a América do Sul obtida a partir destas três fontes; 
(ii) Em seguida, a partir dos dados com resolução diária (1 de janeiro de 2008 a 31 de dezembro de 2015) dos projetos do CHIRPS, TRMM e GPCP, foram calculadas as pêntadas. A análise de Componentes Principais (ACP) (Jolliffe, 2002) foi aplicada a dados pentadais dos três conjuntos de dados com o objetivo de se identificar os principais padrões espaciais de variação da precipitação sobre a América do Sul. Anteriormente à aplicação da ACP, o ciclo sazonal e a tendência linear da série temporal foram removidos. As regiões sudeste $(A 1)$, centroleste (A2) e norte (esta última dividida em A3 e A4) da América do Sul, identificadas na Figura 4, foram selecionadas a partir do padrão espacial do primeiro modo da ACP de forma a possibilitar a comparação entre os conjuntos de dados globais;

(iii) A terceira etapa do trabalho consistiu em comparar o ciclo anual dos dados das EMA com o dos dados globais, CHIRPS, TRMM e GPCP. Foi calculado o BIAS, desvio médio entre os dados mensais das EMA e dados globais, de acordo com a equação;

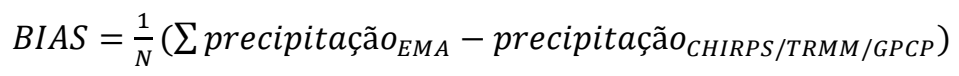

em que $\mathrm{N}$ representa o número de termos da série temporal;

(iv) A quarta etapa do trabalho foi centrada na análise dos resultados do cálculo do coeficiente de correlação linear de Pearson entre as séries temporais de dados das EMA e dados globais (CHIRPS, TRMM e GPCP), para as resoluções diária, pentadal e mensal. O teste de significância estatística t-student foi usado na validação dos resultados;

(v) Com o objetivo de se verificar a possibilidade de representação dos dados (pentadais e mensais) das EMA pelos dados globais, CHIRPS, TRMM e GPCP, foram construídos modelos de regressão linear para as EMA de Joaquim Távora, Ourinhos e Presidente Prudente. Nos resultados, o valor do coeficiente de determinação, expresso por R2, representa a porcentagem da variabilidade da precipitação de cada EMA explicada pelas variáveis independentes (precipitação do CHIRPS, TRMM e GPCP). Nesta etapa, o teste de t-student também foi considerado.

\section{RESULTADOS}

Os resultados obtidos com a análise espacial e temporal dos dados de precipitação dos conjuntos TRMM, GPCP e CHIRPS e a respectiva comparação com as observações nas estações meteorológicas automáticas selecionadas estão subdivididos em três seções. Na primeira seção (3.1), são apresentadas as comparações entre os valores médios anuais e sazonais dos conjuntos de dados do TRMM, GPCP e CHIRPS, sendo também verificada a variabilidade espacial da precipitação relativa ao primeiro modo da ACP aplicada a dados mensais. Na segunda seção (3.2), os dados dos conjuntos globais e os observados nas EMA são comparados, nas escalas diária, pentadal e mensal. O ciclo anual médio da precipitação obtida a partir de cada conjunto de dados é também analisado. Na terceira seção (3.3), são apresentados os resultados de 
simulação da precipitação para as EMA de Ourinho, Joaquim Távora e Presidente Prudente, com base nos dados globais.

\subsection{PRECIPITAÇÃO DO CHIRPS, TRMM E GPCP}

A comparação do valor médio anual para o período selecionado, 20082015, para as três bases de dados globais, CHIRPS, TRMM, GPCP, tal como indicado na Figura 2, permite verificar muitas semelhanças e algumas diferenças entre os dados.

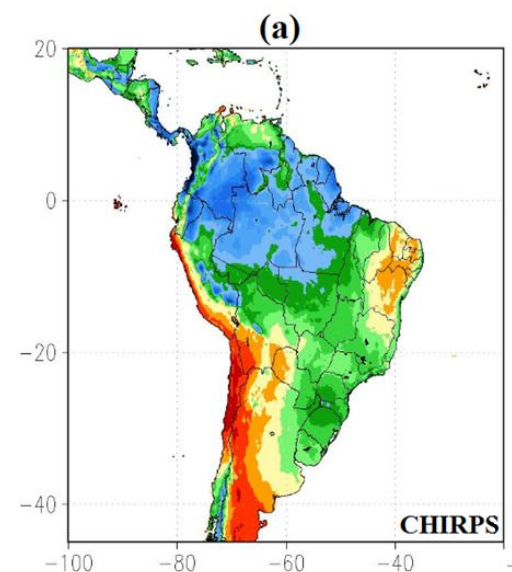

(b)

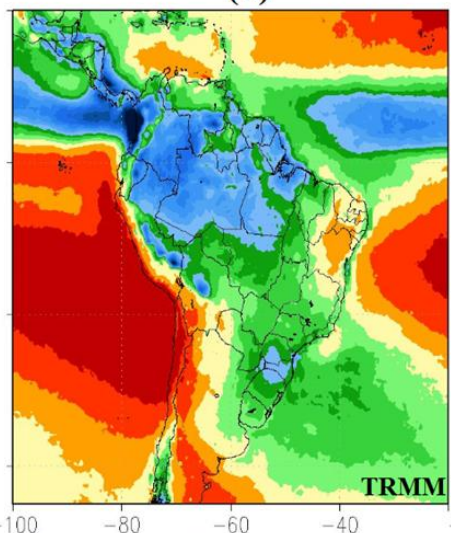

(c)

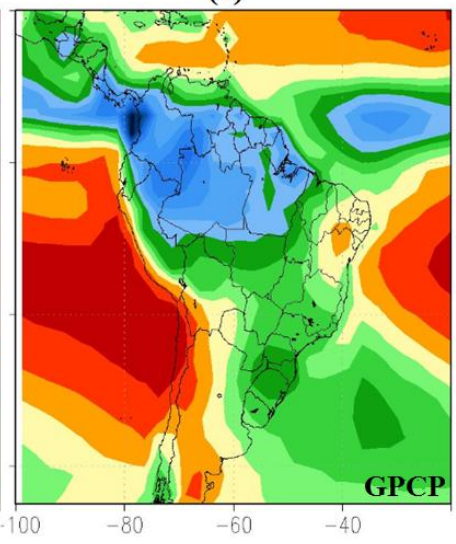

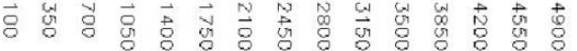

Figura 2 - Precipitação média anual (mm), de janeiro de 2008 a dezembro de 2015, sobre a América do Sul, para os dados do (a) CHIRPS, (b) TRMM e (c) GPCP.

A diferença mais significativa entre os mapas construídos a partir de dados globais é a existência de dados sobre o continente e oceanos, no caso dos dados do TRMM e GPCP, e a ausência de dados nos oceanos, no caso do CHIRPS (Figura 2). Isso se deve ao fato de que o objetivo do projeto CHIRPS é subsidiar estudos sobre insegurança alimentar, dando prioridade à observação da chuva em áreas continentais. Os projetos referentes aos dados do TRMM e GPCP são mais focados em compreender a natureza da distribuição de precipitação e seu papel na liberação de calor latente na atmosfera tropical, particularmente, no caso do TRMM. A consideração de dados de sensoriamento remoto com maior resolução espacial no CHIRPS é evidente nos valores médios anual e sazonal, Figuras 2 e 3.

Os resultados da distribuição espacial dos totais anuais da precipitação pelas três fontes de dados evidenciam semelhanças marcantes. É possível verificar nos dados do CHIRPS (Figura 2a) maior detalhamento espacial da precipitação sobre o continente, quando comparado aos resultados do TRMM e GPCP (Figura 2b, c). Os efeitos da alta resolução dos dados do CHIRPS $\left(0,05^{\circ}\right.$ de resolução) interferem na qualidade da representação. Sobre o continente, as três bases permitem identificar a área da bacia Amazônica com os maiores valores médios de precipitação, superiores a $2.100 \mathrm{~mm}$ ano-1, e, as regiões nordeste do Brasil, extremo oeste e sudoeste da América do Sul com os 
menores valores, inferiores a $700 \mathrm{~mm}$ ano-1. Na região nordeste da América do Sul, é possível verificar como os dados do CHIRPS e TRMM retratam com maior precisão, em relação aos dados do GPCP, a variabilidade espacial do valor médio anual, de forma que uma extensão maior desta região apresenta valor médio anual de precipitação entre 350 e $700 \mathrm{~mm}$ para os dados do CHIRPS e TRMM, enquanto os dados do GPCP apresentam uma área menor para esta mesma faixa de precipitação. A melhor definição dos índices pluviométricos deve contribuir para a caracterização mais precisa do bioma característico de cada região. No sudeste do continente sulamericano (região sul do Brasil), o valor médio anual de chuva varia entre 1.050 e $1.750 \mathrm{~mm}$ para os três conjuntos de dados. A faixa de precipitação orientada na direção noroeste-sudeste, com valores anuais relativamente altos (entre 1.400 e $5.000 \mathrm{~mm}$ ), coincidente com o posicionamento médio da Zona de Convergência do Atlântico Sul (ZCAS) (Kodama, 1992), é caracterizada pelos três conjuntos de dados. Na região sul do Brasil, sobre a Serra Geral, os dados do TRMM representam precipitação média anual mais elevada, entre 2.100 e $2.450 \mathrm{~mm}$. Para esta mesma área, os dados do CHIRPS e GPCP indicam valores de precipitação variando de 1.750 a 2.010. A diferença média, portanto, entre o TRMM e CHIRPS ou entre o TRMM e o GPCP fica próxima a $350 \mathrm{~mm}$. A alta precipitação observada sobre a região sul do Brasil está associada à frequente instabilização da atmosfera ligada a passagem de sistemas frontais (Taljaard, 1967 e Kousky, 1979). A validação dos valores de precipitação estimados para esta área, sudeste da América do Sul, será apresentada na seção 3.3, em relação a dados observados localmente nas estações meteorológicas. Outro exemplo que ilustra as diferenças obtidas pela resolução espacial da precipitação dentre os dados globais pode ser visto na estreita faixa que se estende do norte do estado do Pará até sua região sudeste, com precipitação média anual entre 1.750 e $2.100 \mathrm{~mm}$. A faixa de precipitação do GPCP, entre 1.750 e 2.100 mm, apresenta direção mais meridional do que os dados do TRMM e CHIRPS, o que pode ser um problema gerado no processo de interpolação de dados. Ainda, o setor oeste do Paraguai e a vertente leste da Cordilheira dos Andes, que se estende na direção meridional entre $18^{\circ} \mathrm{S}$ e $27^{\circ} \mathrm{S}$, com precipitação média anual entre 350 e 700 $\mathrm{mm}$, apresenta áreas com dimensões distintas nas três fontes de dados consideradas. Os dados do CHIRPS e TRMM indicam a existência de áreas com precipitação média anual elevada sobre o Peru e Bolívia, provavelmente determinada pela elevação topográfica na vertente leste dos Andes, aspecto não observado no conjunto do GPCP. Verifica-se que os dados do CHIRPS expressam a ocorrência de valores médios anuais mínimos e máximos em áreas mais extensas, o que pode estar associado à maior resolução espacial dos dados.

Sobre a faixa equatorial dos oceanos Atlântico e Pacífico, a precipitação do TRMM e GPCP (Figura 2b, c) apresenta valores anuais superiores a 2.100 mm, o que está associado à atuação da Zona de Convergência Intertropical (ZCIT) (Pielke, 1971). Tanto ao sul como ao norte da ZCIT, sobre os oceanos, estas duas fontes de dados indicam baixos valores de precipitação anual (inferiores a $700 \mathrm{~mm}$ ano-1), respondendo à influência das regiões de alta pressão subtropical nos hemisférios sul e norte. Contudo, os dados do TRMM indicam maior variabilidade espacial da precipitação. O padrão médio espacial obtido para o período de 2008 a 2015 é comumente observado em estudos relativos à climatologia da América do Sul (Dyer, 1979; Reboita et al., 2010; etc). 
A comparação entre os valores médios sazonais de precipitação obtidos com os dados do CHIRPS, TRMM e GPCP (Figura 3) mostra que em todas as estações do ano os resultados da distribuição do GPCP apresentam menor detalhamento espacial em relação aos dados do CHIRPS e TRMM, porém, as intensidades entre as três bases se assemelham. Durante o verão, o valor médio mensal mais elevado ocorre no sul dos estados do Amazonas e Pará, nas três fontes de dados, chegando a valores entre 400 e $550 \mathrm{~mm}$ para as três bases de dados utilizadas (Figura $3 a, c$ ). Sobre o setor leste do nordeste da América do Sul (região semiárida) é possível observar diferenças entre as três fontes de dados globais de precipitação: enquanto os valores mensais de precipitação do CHIRPS variam entre 25 e $50 \mathrm{~mm}$ nesta região, os valores do GPCP variam entre 50 e $100 \mathrm{~mm}$, o que chega a ser duas vezes maior que o valor estimado pelo CHIRPS. Para o TRMM, os valores não são tão detalhados como nos dados do CHIRPS, mas é possível identificar regiões com valores entre 25 e $50 \mathrm{~mm}$. As diferenças entre os dados do CHIRPS e GPCP sobre o Nordeste do Brasil indicam o efeito da alta resolução espacial. Os valores mais intensos de chuva durante o verão (DJF) aparecem sobre o centro da América do Sul, na direção noroeste-sudeste, ligando a região da bacia amazônica à região sudeste do Brasil e coincidindo com o posicionamento médio da ZCAS (Kodama, 1992). Assim, enquanto o valor médio anual de precipitação para as três fontes de dados globais, CHIRPS, TRMM e GPCP, apresentam diferenças mais suaves, a diferença da precipitação estimada do GPCP durante o verão, por exemplo, alcança valores mais altos, como no caso do setor leste do nordeste do Brasil, alcançando duas vezes o estimado pelo CHIRPS e TRMM.

A distribuição espacial da precipitação média na estação de outono apresenta padrões bastante semelhantes entre as bases do CHIRPS, TRMM e GPCP. Em geral, os maiores valores de precipitação durante o outono são encontrados no extremo norte da América do Sul (Figura 3d, f), com diferenças na resolução dos dados. Os valores médios de precipitação mensal sobre esta região variam entre 300 e $400 \mathrm{~mm}$ para as três bases de dados. Nas demais regiões do continente sulamericano, verifica-se a diminuição da precipitação de outono nas três fontes de dados quando comparada aos valores de verão. Sinais mais intensos de chuva no extremo norte do continente estão associados à migração da ZCIT para latitudes mais ao norte durante o outono, o que também é resposta da diminuição da convecção local e precipitação em grande parte do continente (Pielke, 1971).

Para o período de inverno, as três bases de dados indicam os mais baixos valores de precipitação sobre o centro-leste e sudoeste do continente, com valores médios mensais inferiores a $12 \mathrm{~mm}$. Tal como o verificado para o período de outono e verão, os valores de precipitação das bases do CHIRPS e TRMM durante o inverno apresentam mais detalhamento, devido à maior resolução espacial, sendo mais semelhantes entre si, e mais distintos dos dados compilados pelo GPCP. As áreas com menor volume médio mensal de precipitação durante o inverno (precipitação $<12 \mathrm{~mm}$ ) encontram-se no centro da América do Sul, para as bases do CHIRPS, TRMM e GPCP (Figura 3g, i). Na região sudeste da América do Sul, os valores mais altos da precipitação durante o inverno estão também associados à passagem de sistemas frontais (Taljaard, 1967; Kousky, 1979), assim como no sudoeste do continente. As três bases de dados apresentam valores médios para a precipitação de inverno na região sudeste da América do Sul entre 50 e 150 mm. Durante o inverno, é possível 
verificar a intensificação do período seco na região nordeste do Brasil e no sul da bacia Amazônica para as três fontes de dados globais quando comparados aos valores de precipitação nas estações de outono e verão. Do ponto de vista da variação sazonal, a primavera marca o início do período chuvoso sobre grande parte do continente, o que pode também é observado nas três fontes de dados (Figura $3 j-1$ ). 

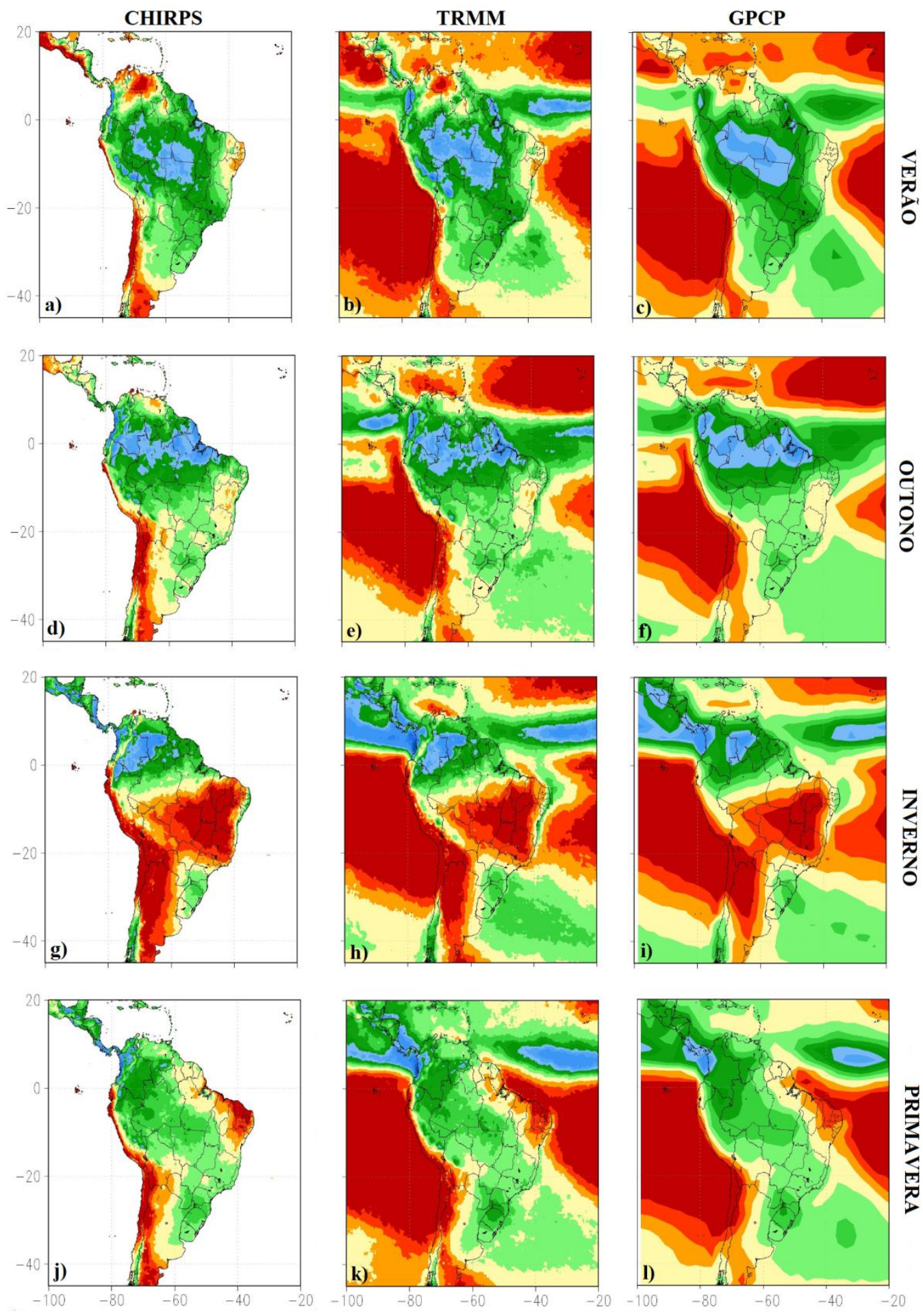

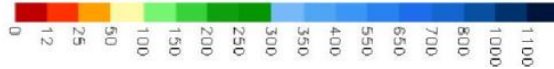

Figura 3 - Precipitação média sazonal ( $m m$ mês-1) sobre a América do Sul para as estações de (a-c) verão (DJF), (d-f) outono (MAM), ( $g-h)$ inverno (JJA) e (j-k) primavera (SON), para os dados do CHIRPS (coluna à esquerda), TRMM (coluna do meio) e GPCP (coluna à direita), entre 2008 e 2015. 
Com o objetivo de identificar a variabilidade espacial dos dados de precipitação sobre a América do Sul, a Análise de Componentes Principais foi aplicada aos dados pentadais das três bases. Os resultados indicam padrões espaciais bastante semelhantes entre si para os conjuntos de dados considerados (Figura 4), apesar do tamanho relativamente pequeno da série temporal, de 01 de janeiro de 2008 a 31 de dezembro de 2015. O primeiro modo da ACP permite identificar três regiões homogêneas quanto à variabilidade da precipitação na América do Sul, denominadas aqui de sudeste - A1, centroleste - A2, noroeste e norte - A3 e A4.

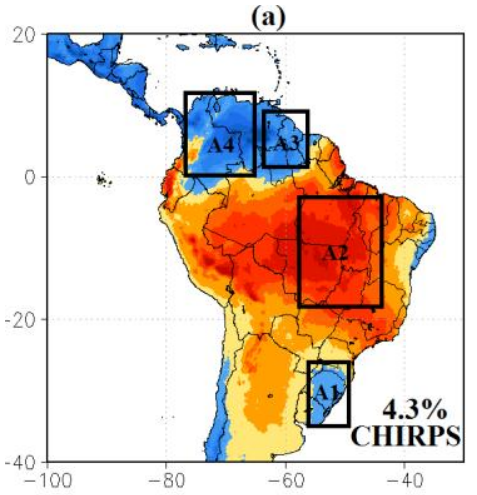

(b)

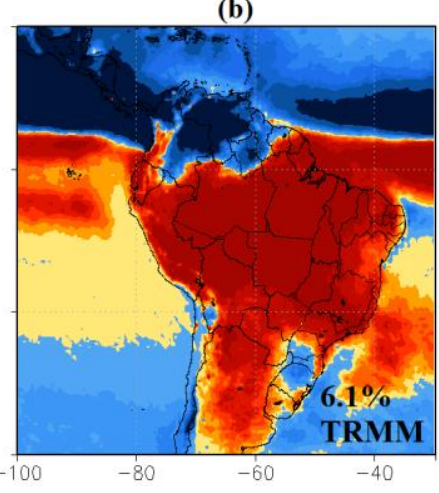

(c)

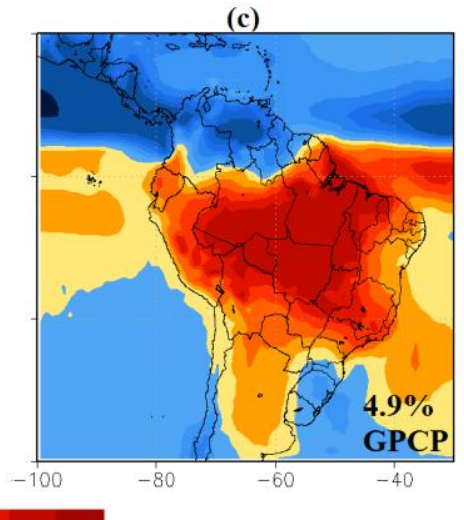

$\begin{array}{lllllllllllll}-4 & -2.5 & -2 & -1.5 & -1 & -0.5 & 0 & 0.5 & 1 & 1.5 & 2 & 2.5 & 4\end{array}$

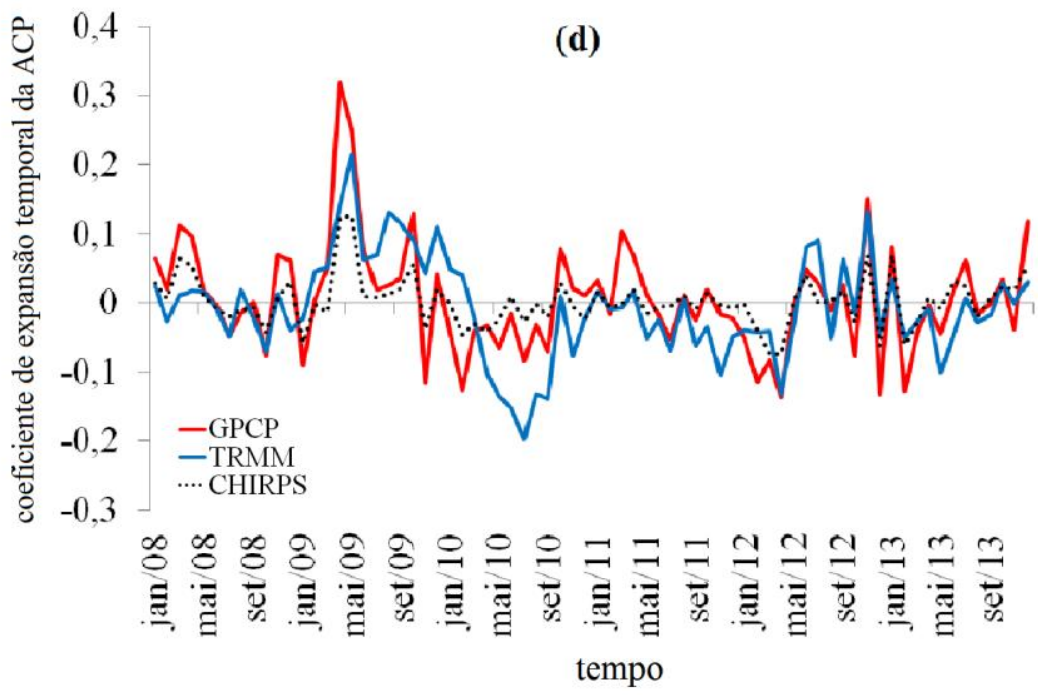

Figura 4 - Primeiro modo espacial da ACP aplicada aos valores de precipitação pentadal dos conjuntos de dados (a) CHIRPS, (b) TRMM e (c) GPCP, entre 01 de janeiro de 2008 e 31 de dezembro de 2015. A explicação da variância do dado original associada ao primeiro modo da ACP está indicada em cada quadro. (d) Coeficiente de expansão temporal relativo ao primeiro modo da ACP para as bases do GPCP (curva vermelha), TRMM (curva azul) (dividido por 2) e CHIRPS (curva pontilhada). As áreas definidas pelos retângulos no painel (a) por $\mathrm{A} 1, \mathrm{~A} 2, \mathrm{~A} 3$ e $\mathrm{A} 4$ são delimitadas, respectivamente por $\left(50^{\circ}\right.$ $\mathrm{W}-59^{\circ} \mathrm{W}$ e $\left.25^{\circ} \mathrm{S}-35^{\circ} \mathrm{S}\right),\left(40^{\circ} \mathrm{W}-54^{\circ} \mathrm{W}\right.$ e $\left.3^{\circ} \mathrm{S}-17^{\circ} \mathrm{S}\right),\left(50^{\circ} \mathrm{W}-60^{\circ} \mathrm{W}\right.$ e $3^{\circ} \mathrm{N}$ e $7^{\circ}$ N) e $\left(62^{\circ} \mathrm{W}-78^{\circ} \mathrm{W}\right.$ e $\left.1^{\circ} \mathrm{N}-11^{\circ} \mathrm{N}\right)$. 
O extremo sudoeste da América do Sul também constitui uma área com variabilidade homogênea. A faixa litorânea do nordeste só aparece para os dados do CHIRPS. Contudo, como se sabe que a variabilidade da precipitação desta área é distinta da variabilidade do semiárido (Kousky, 1979 e Gan e Kousky, 1986), sugere-se que os dados do CHIRPS representem melhor a precipitação, em geral. O sudeste da América do Sul (área A1) apresenta valores mensais semelhantes para os três conjuntos de dados. As demais áreas, A2-A4, apresentam maior semelhança entre os dados mensais do CHIRPS e TRMM, sendo os dados do GPCP os mais distintos.

O primeiro modo da ACP explica respectivamente 4,3\%, 6,1\% e 4,9\% da variância da precipitação pentadal na América do Sul para os dados do CHIRPS, TRMM e GPCP, no período considerado. A diferença mais significativa entre os padrões espaciais deste modo da ACP aplicada aos dados de precipitação dos três conjuntos globais refere-se à intensidade dos valores espaciais, sendo o TRMM o conjunto que apresenta os maiores valores, sugerindo maior variabilidade da precipitação deste conjunto, mostrado na Figura 4. Além dos dados do padrão espacial do TRMM (Figura 4b) serem mais intensos que os dos demais conjuntos de dados, o respectivo coeficiente de expansão temporal é aproximadamente duas vezes o valor do coeficiente do CHIRPS e GPCP (Figura 4d). Outro ponto que merece ser destacado pela aplicação de ACP aos dados do CHIRPS é a identificação da área da faixa leste do nordeste do Brasil, o que provavelmente está associado à alta resolução dos dados. Esta área apresenta precipitação mais intensa durante a estação de inverno do hemisfério sul devido à intensificação dos alíseos e da alta subtropical do Atlântico Sul (Kousky, 1979), com atuação adicional de ondas de leste (Riehl, 1945 e Chou, 1990). Este sinal não é identificado nos outros dois conjuntos de dados globais. Grande parte do Uruguai e sul do Brasil merecem atenção uma vez que os dados do CHIRPS apresentam um padrão distinto do obtido com os dados do TRMM. O padrão da primeira ACP com os dados do CHIRPS (Figura 4a) mostra valores negativos apenas no setor leste do Uruguai e Rio Grande do Sul enquanto o padrão relativo aos dados do TRMM apresenta valores positivos sobre o Uruguai e, negativos, sobre o Rio Grande do Sul, Santa Catarina e sul do Paraná, evidenciando diferenças entre os conjuntos de dados.

Os valores de correlação linear entre a precipitação mensal das áreas $A 1$, A2, A3 e A4, para os dados das três fontes, CHIRPS, TRMM e GPCP, são bastante elevados, superiores a 0,90, tal como indicado na Tabela 1 , exceto para a área A3 (norte da AS), na comparação entre dados do TRMM e CHIRPS, cujo valor de correlação é igual a 0,86 . Todos os valores do coeficiente de correlação linear apresentam nível de significância para $p=0,05$ (t-Student). 0 sudeste (área A1) e o centro-leste (área A2) da América do Sul apresentam os maiores valores de correlação linear entre as três fontes consideradas, o que também pode ser visto pela evolução temporal da precipitação média nas respectivas áreas, como mostrado na Figura 5. 


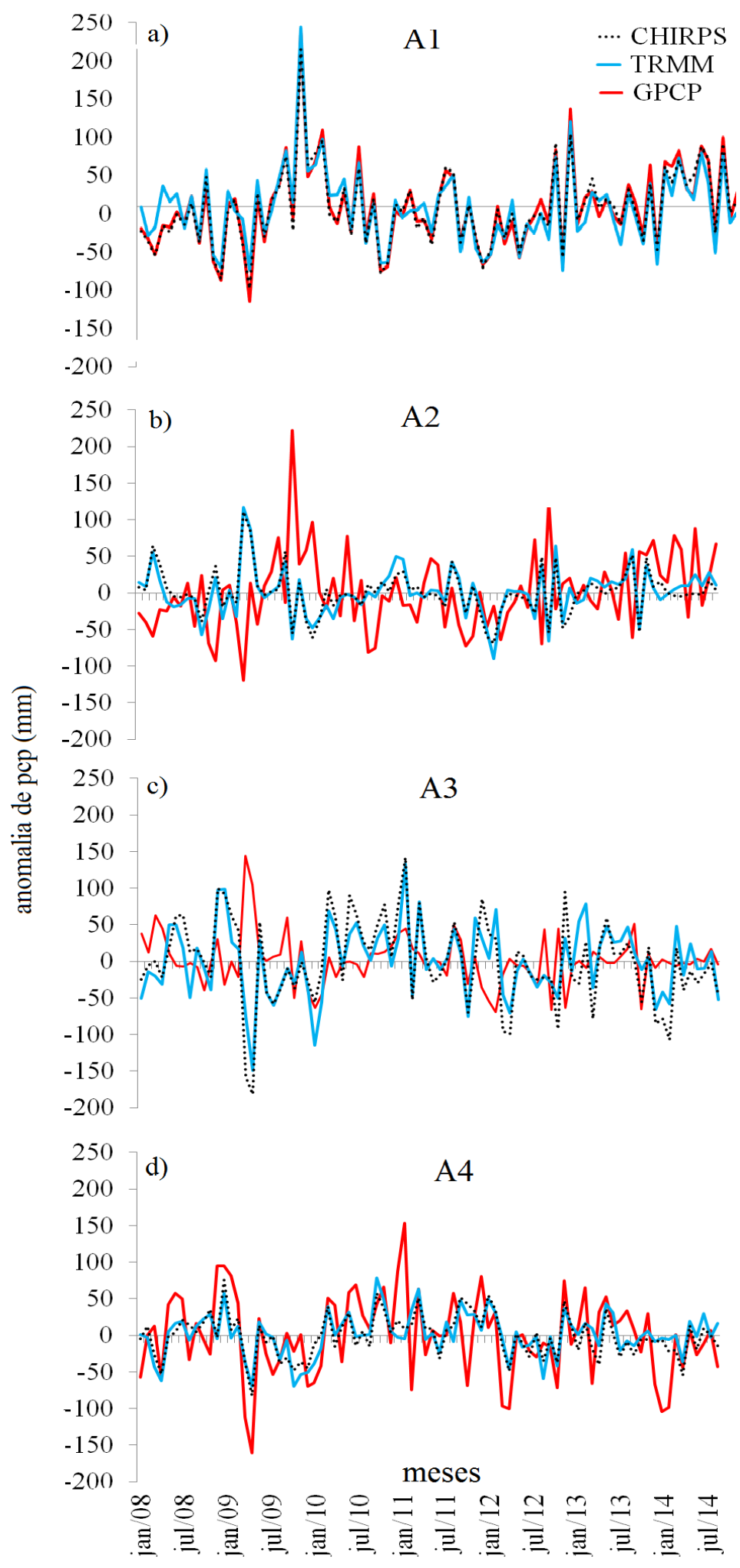

Figura 5 - Precipitação mensal nas áreas (a) $A 1$, (b) $A 2$, (c) $A 3$ e (d) A4 para os dados do CHIRPS, TRMM e GPCP, entre janeiro de 2008 e dezembro de 2015. 
Tabela 1 - Coeficiente de correlação linear entre dos dados de precipitação mensal do CHIRPS, TRMM e GPCP, para o período de janeiro de 2008 a dezembro de 2015, para as áreas A1-A4 (identificadas na Figura 4). Todos os valores apresentam nível de significância estatística para $p=0,05$ (t-Student).

\begin{tabular}{l|c|c|c} 
& GPCP $\mathbf{x}$ TRMM & GPCP $\mathbf{x}$ CHIRPS & TRMM x CHIRPS \\
\hline A1 : sudeste da América do Sul & 0,94 & 0,98 & 0,93 \\
A2 : centro-leste da América do Sul & 0,93 & 0,96 & 0,93 \\
A3 : norte da América do Sul & 0,90 & 0,95 & 0,86 \\
A4 : noroeste da América do Sul & 0,93 & 0,94 & 0,90 \\
\hline
\end{tabular}

\subsection{CICLO ANUAL MÉdIO DA PRECIPITAÇÃO - EMA, CHIRPS, TRMM E GPCP}

A avaliação da variabilidade da precipitação observada nas EMA, na escala diária, pentadal e mensal e a estimada nos conjuntos de dados globais foi feita com base no cálculo do coeficiente de correlação linear entre os diversos conjuntos de dados. O bias para dados diários, pentadais e mensais também foi calculado.

O ciclo anual médio dos dados das EMA (Figura 6), nos municípios de Paranaponema, Joaquim Távora, Ourinhos e Presidente Prudente, e dados globais indicam valores mínimos durante o inverno austral e máximos durante o verão (Figura 6), exceto no caso da EMA-PARA para os dados do TRMM e GPCP (Figura 6a), sendo, contudo, os valores mínimos observados entre janeiro e março. Em média, para as quatro localidades consideradas, o ciclo anual médio tal como indicado pelas EMA é mais bem representado pelos dados do CHIRPS, como evidenciado na Tabela 2, que mostra os menores desvios médios entre os dados do CHIRPS e das EMA. Os dados do TRMM apresentam as maiores diferenças para o ciclo anual médio em relação ao obtido nas EMA.

Tabela 2 - Desvio médio anual (mm), BIAS, entre a precipitação observada nas EMA e a obtida das bases do CHIRPS, GPCP e TRMM.

\begin{tabular}{cccc}
\hline & BIAS CHIRPS & BIAS GPCP & BIAS TRMM \\
\hline PARANAPONEMA & 2,09 & 2,65 & 4,39 \\
OURINHOS & 1,70 & 2,24 & 2,47 \\
JOAQ. TÁVORA & 1,60 & 2,12 & 1,82 \\
PRES. PRUDENTE & 1,80 & 4,59 & 5,08 \\
\hline
\end{tabular}




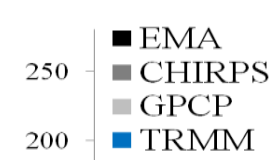

(a)
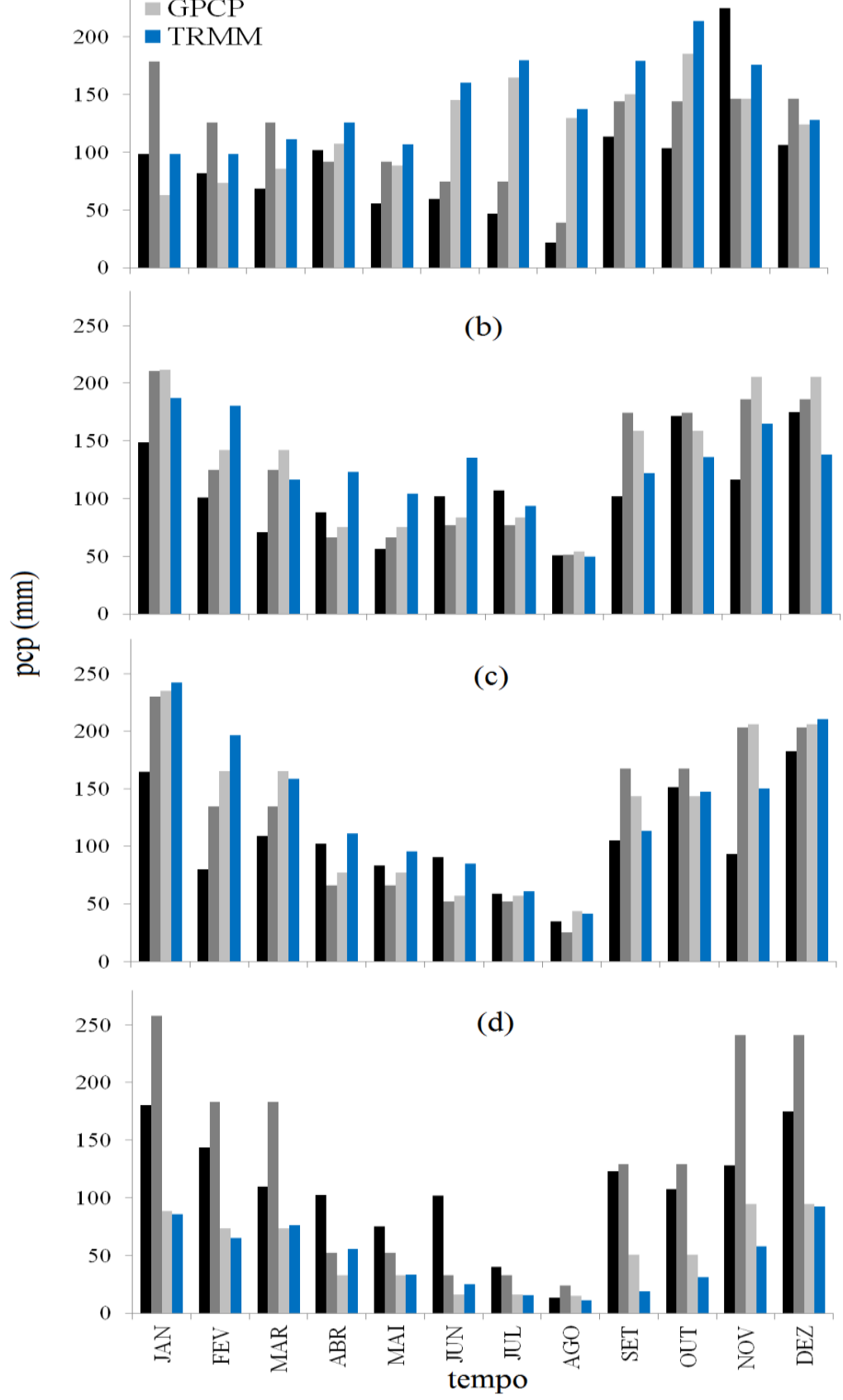

Figura 6 - Ciclo médio anual para o período de janeiro de 2008 a dezembro de 2015, para os municípios de (a) Paranaponema, (b) Joaquim Távora; (c) Ourinhos e (d) Presidente Prudente, para os dados das EMA (curva preta contínua), CHIRPS (curva cinza), GPCP (curva pontilhada) e TRMM (curva tracejada).

Em poucos casos o coeficiente de correlação linear entre dados diários de precipitação observados nas EMA é significativo sendo sempre inferior a 0,15, tal como indicado na Figura 7, exceto para o caso da EMA-PPRU, em que o 
coeficiente de correlação é igual a 0,58 e 0,53 (significativos estatisticamente) em relação aos dados do CHIRPS e GPCP, respectivamente. Assim, apenas no caso da EMA-PPRU, dados na escala diária podem ser eventualmente comparáveis aos dados do CHIRPS e GPCP. Este resultado sugere que no caso de análises de dados na escala diária, o uso de dados de precipitação obtida a partir das fontes de dados globais seja realizada criteriosamente. Os dados diários do CHIRPS e GPCP apresentam altos valores de correlação $(>0,79)$ em cada uma das quatro localidades consideradas, sendo sempre significativos.

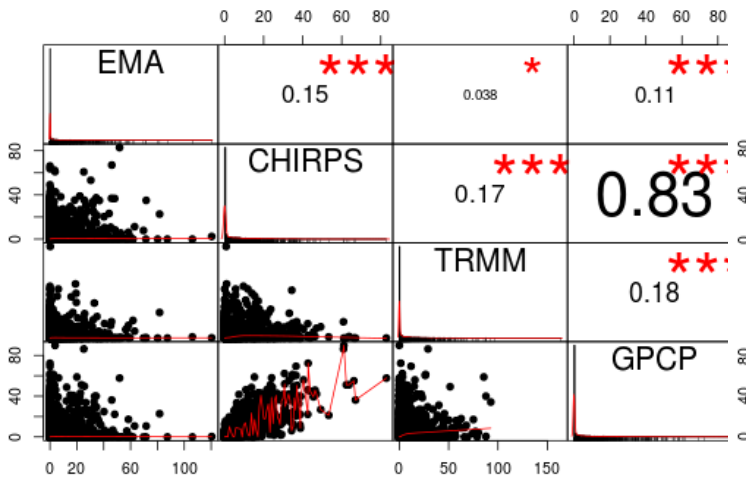

(a)

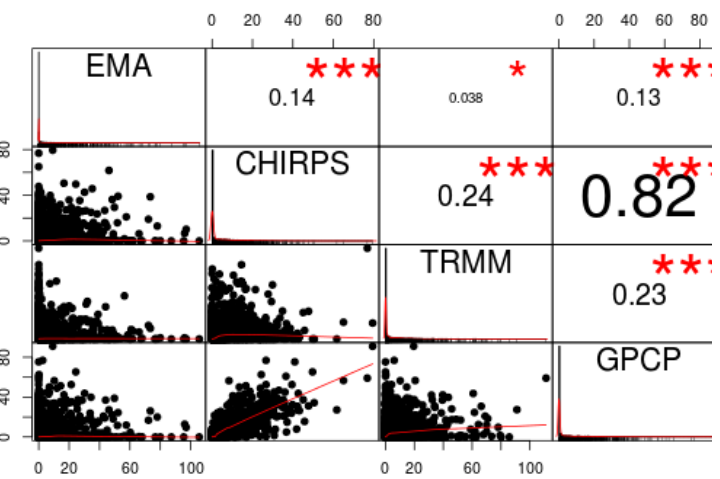

(b)

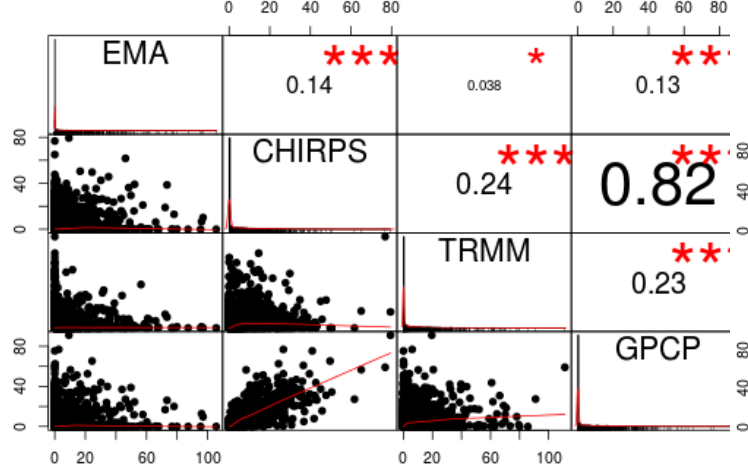

(c)

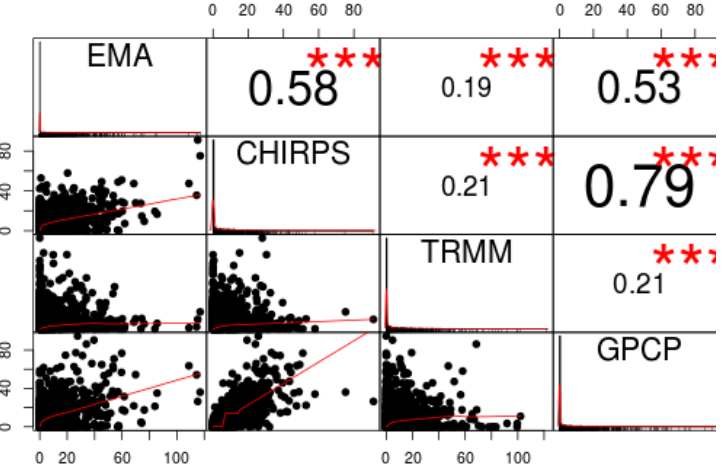

(d)

Figura 7 - Diagrama de dispersão e coeficiente de correlação linear $(r)$ entre os dados de precipitação diária do CHIRPS, TRMM e GPCP e a precipitação observada na (a) EMAJOTA, (b) EMA-OURI, (c) EMA-PARA e (d) EMA-PPRU, entre 01 de janeiro de 2008 e 31 de dezembro de 2015. Os valores indicados nos painéis representam o valor de $r$. As estrelas representam o grau de significância estatística (t-Student), sendo uma, duas e três estrelas referentes respectivamente a valores de $p$ iguais a $0,05,0,025$ e 0,005 .

$\mathrm{Na}$ escala pentadal, os resultados de correlação linear mostram, em comparação aos obtidos para dados diários (Figura 7), mais casos de valores relativamente altos (Figura 8 ), tanto entre os dados das próprias fontes globais como entre os dados das fontes globais e os dados observados nas estações automáticas. Este aspecto é visível através da comparação dos diagramas de dispersão para cada par de séries temporais elaborados para as escalas diária e pentadal, mostrados nas figuras 7 e 8, respectivamente. Para dados de precipitação pentadal, os maiores valores do coeficiente de correlação linear são observados entre os dados do GPCP e TRMM, superiores a 0,70 (e significativos) 
para as quatro localidades consideradas. Tanto os dados do GPCP como os dados do TRMM, em escala pentadal, apresentam correlação relativamente alta $(r>0.60)$ e significativa em relação aos dados observados na EMA-PARA e EMAPPRU (Figura 8c,d). Apesar de os dados do CHIRPS apresentarem alta resolução espacial ( $5 \mathrm{~km}$, próximo ao equador), não apresentam as mais altas correlações quando comparados aos dados das EMA, tanto na escala diária como pentadal.

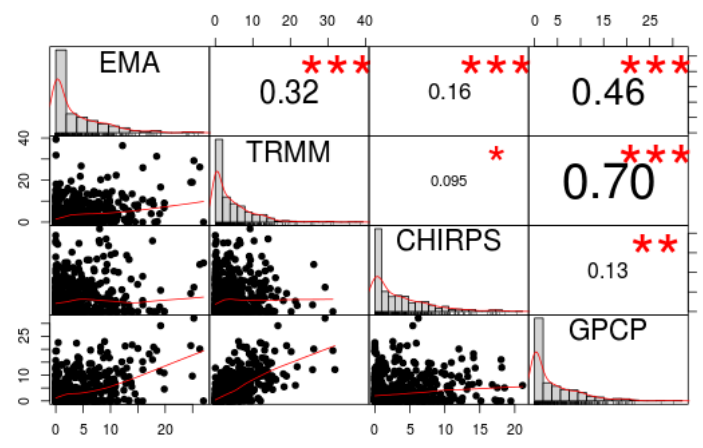

(a)

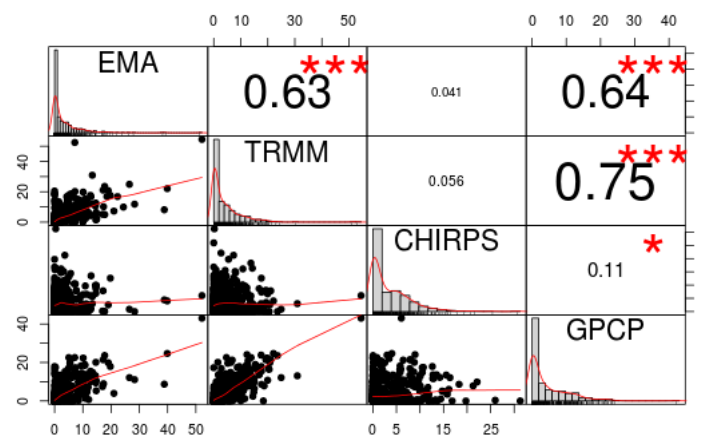

(c)

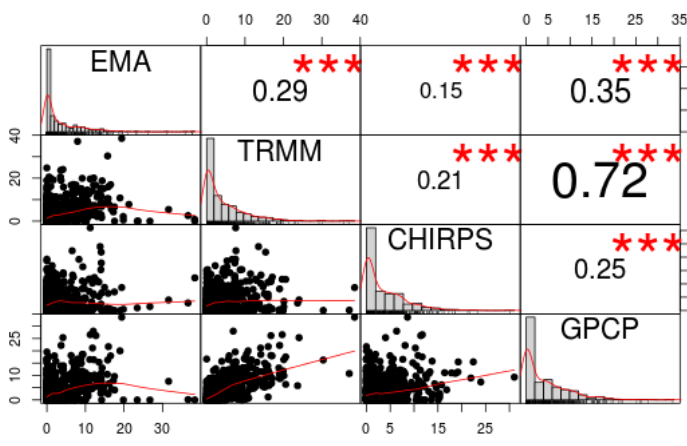

(b)

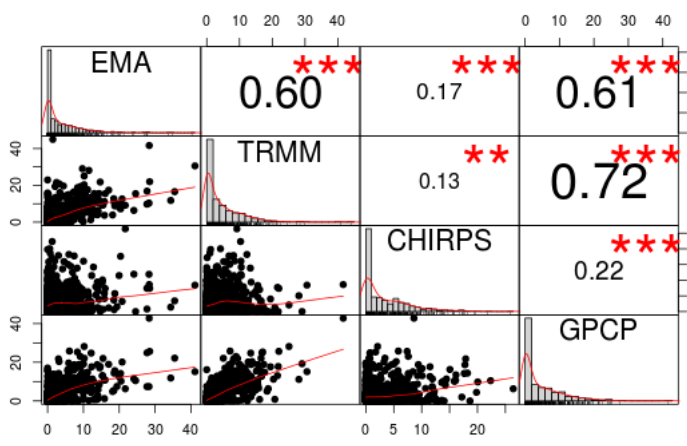

(d)

Figura 8 - Idem à Figura 7, mas para dados de precipitação pentadal.

$\mathrm{Na}$ escala mensal, os dados das fontes globais mais bem correlacionados aos dados das estações automáticas consideradas são os dados do TRMM, tal como indicado na Figura 9, com valores iguais a 0,68, 0,65, 0,51 e 0,40, respectivamente, para a EMA-JOTA, EMA-OURI, EMA-PARA e EMA-PPRU. Resultados semelhantes de correlação foram encontrados por Pereira et al. (2013) ao comparar a precipitação mensal estimada pelo TRMM à precipitação de 183 estações meteorológicas do INMET distribuídas por todo o Brasil, entre 1997 e 2010. Os dados mensais do CHIRPS são relativamente bem correlacionados com os dados observados nas estações automáticas EMA-JOTA, EMA-OURI e EMA-PPRU, com valores iguais a 0,58, 0,48 e 0,47 (todos significativos). No caso da EMA-PARA, a correlação linear com os dados mensais do CHIRPS é igual a 0,22. Os dados do GPCP também apresentam correlação relativamente alta em relação aos dados da EMA-JOTA, EMA-OURI e EMA-PPRU (respectivamente, $0,58,0,48,0,45$ ) na escala mensal, exceto, novamente, para a EMA-PARA, que apresenta valor igual a 0,13. Verifica-se que a EMA-PARA é a que apresenta os menores valores do coeficiente de correlação linear em relação 
a todos os conjuntos de dados considerados, o que leva a supor que os dados desta estação possam estar associados a alguma especificidade local, de forma que a representação por dados dos conjuntos globais seja relativamente inadequada, ou, que os dados observados na própria EMA sejam de baixa qualidade. Valores de correlação linear entre os dados mensais do GPCP e CHIRPS $(0,90,0,89,0,88$ e 0,77), GPCP e TRMM $(0,57,0,76,0,55$ e 0,77) e TRMM e CHIRPS $(0,53,0,67,0,62,0,67)$ nas localidades das quatro EMA consideradas (EMA-JOTA, EMA-OURI, EMA-PARA e EMA-PPRU) são relativamente altos. Os valores do coeficiente de correlação na escala mensal (Figura 9) são, em média, quatro vezes maiores do que os obtidos para dados na escala diária (Figura 7) para a EMA-JOTA, EMA-PARA e EMA-OURI, considerando todas as bases de dados. No caso da EMA-PPRU, o coeficiente de correlação para a precipitação diária é mais alto do que o obtido para as demais localidades ( $r=$ 0,53, na EMA-PPRU, e $r \leq 0,13$, nas demais estações automáticas).

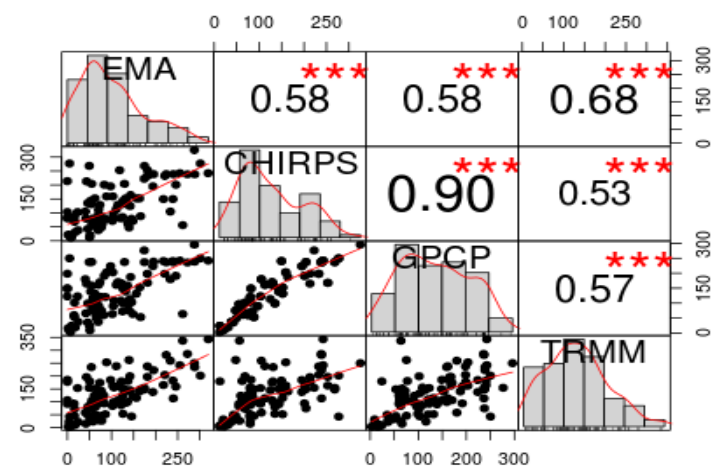

(a)

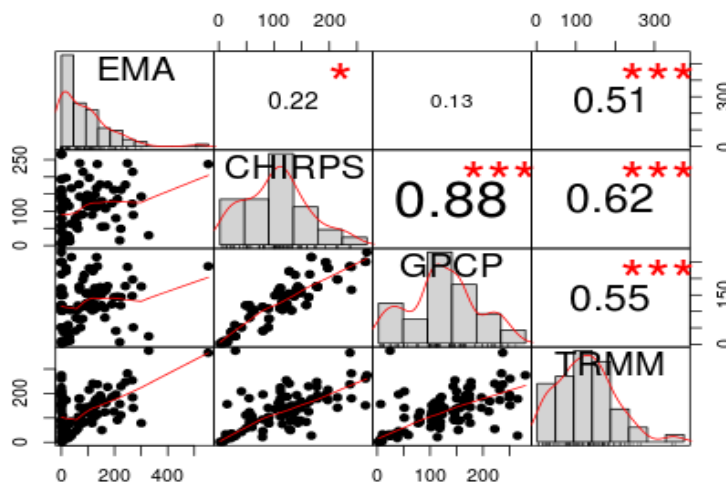

(c)

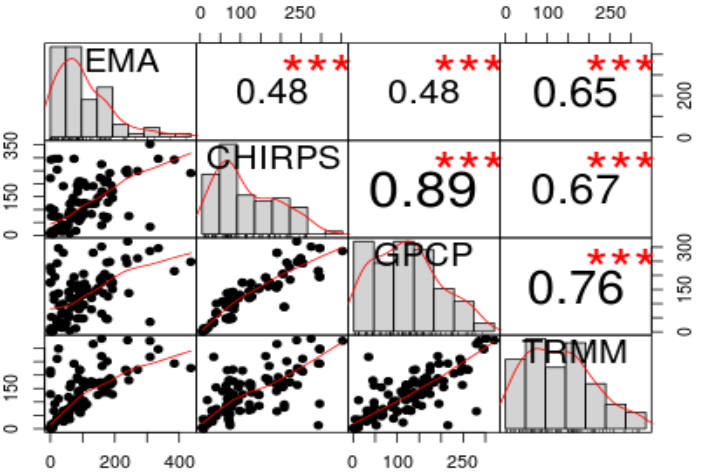

(b)

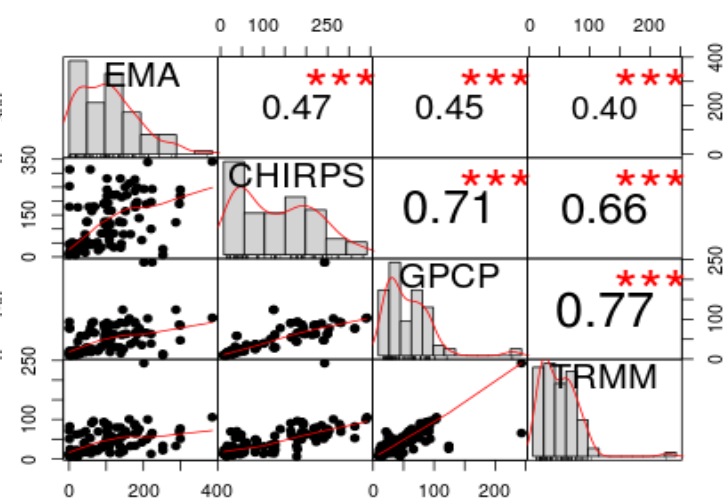

(d)

Figura 9 - Idem à Figura 7, mas para dados de precipitação mensal.

\subsection{SIMULAÇÃO DA PRECIPITAÇÃO PENTADAL E MENSAL}

Os resultados apresentados pelas análises de correlação entre dados de precipitação do CHIRPS, TRMM e GPCP e das estações automáticas de Joaquim Távora, Ourinhos, Paranaponema e Presidente Prudente mostraram, nas várias escalas, altos valores de correlação linear estatisticamente significativos, o que sugere a possibilidade de representação de dados faltantes nas séries temporais 
das estações automáticas por dados dos conjuntos globais. Após a análise dos resultados de ajustes lineares para as quatro estações automáticas, mostramos aqui os referentes à estação de Presidente Prudente, na escala pentadal, Joaquim Távora e Ourinhos, na escala diária.

O ajuste linear entre a precipitação pentadal de Presidente Prudente e os dados do TRMM e GPCP apresenta coeficiente de determinação igual a 47\%. As séries temporais da precipitação observadas na EMA-PPRU e a simulada pelo ajuste linear na escala pentadal são apresentadas na Figura 10 . No caso de dados na escala mensal, os melhores ajustes foram obtidos para as EMA de Joaquim Távora e Ourinhos (Figura 11), com coeficientes de determinação iguais a $55 \%$ e $45 \%$, respectivamente. No caso da EMA-JOTA, os conjuntos do CHIRPS e TRMM são os que provêm o melhor ajuste. No caso da EMA-OURI, o melhor ajuste linear foi definido com base nos três conjuntos de dados globais.

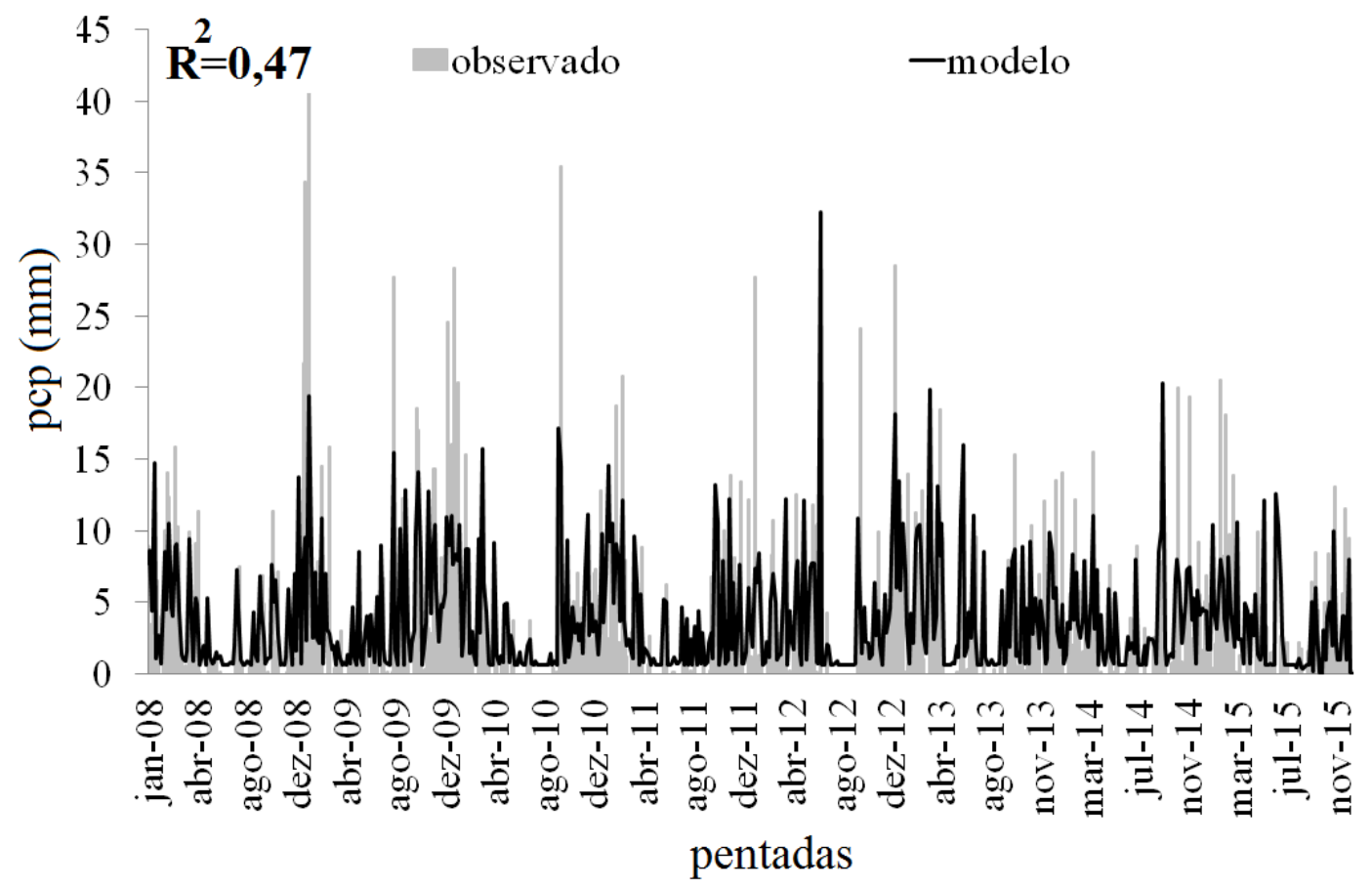

Figura 10 - Precipitação pentadal simulada (curva preta) e observada (curva cinza) para a EMA de Presidente Prudente, entre janeiro de 2008 e dezembro de 2015. 
(a)

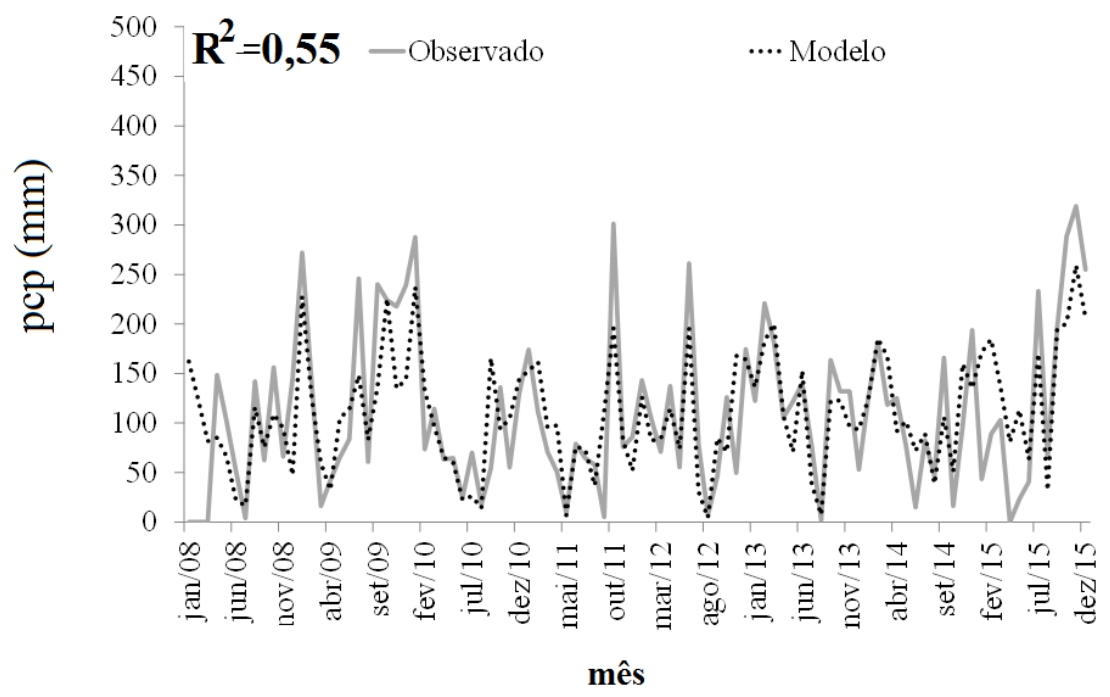

(b)

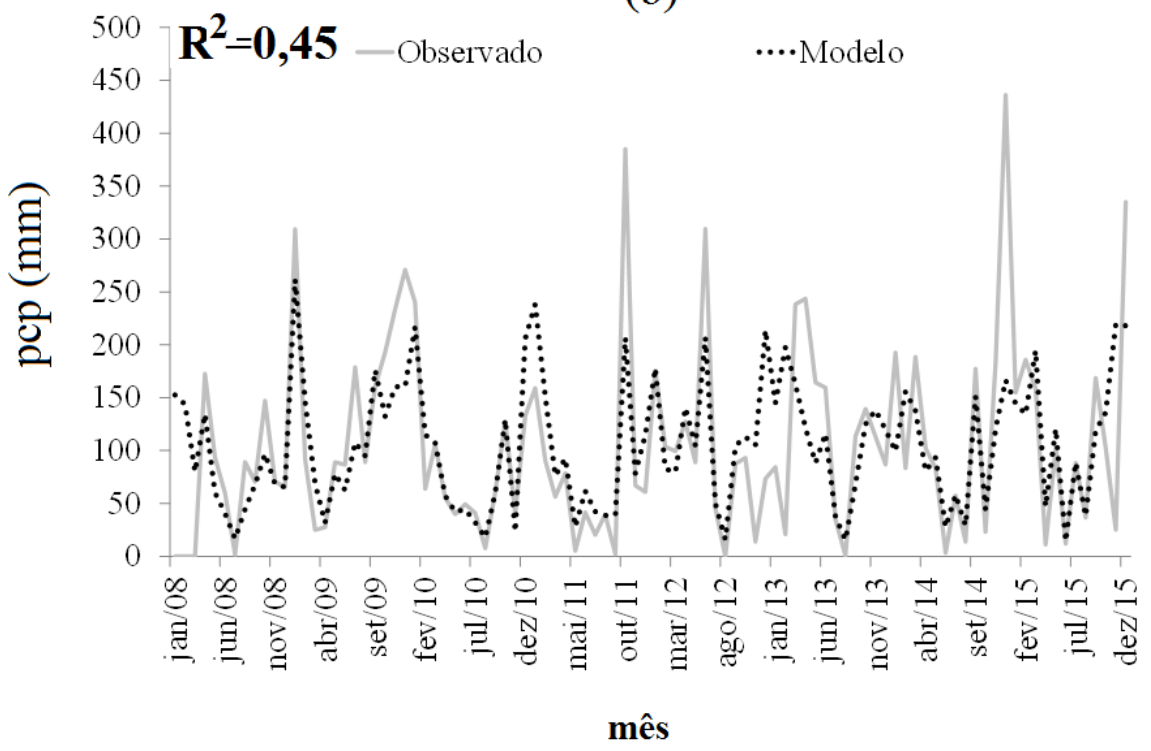

Figura 11 - (a) Precipitação mensal simulada e observada para a EMA de (a) Joaquim Távora e de (b) Ourinhos entre janeiro de 2008 e dezembro de 2014.

\section{CONSIDERAÇÕES FINAIS}

Neste estudo apresentamos a comparação entre os dados de precipitação dos projetos CHIRPS, GPCP e TRMM e dados de precipitação observada em quatro estações meteorológicas automáticas localizadas na região sudeste da América do Sul, nos municípios de Ourinhos, Presidente Prudente, Joaquim 
Távora e Paranaponema, no período de 01 de janeiro de 2008 a 31 de dezembro de 2015.

Os resultados mostram que os padrões espaciais da precipitação média anual e sazonal sobre a América do Sul obtidos para as três fontes de dados globais são semelhantes entre si, havendo, porém, maior semelhança entre os dados do CHIRPS e TRMM. É possível perceber o maior detalhamento espacial da precipitação tanto para os dados do $\operatorname{CHIRPS}(0,05$ grau de resolução) como para os dados do TRMM (0,25 grau de resolução) em relação aos dados do GPCP (2,5 graus de resolução), permitindo a melhor definição da extensão de áreas áridas e chuvosas na América do Sul, como o setor nordeste e noroeste do continente.

A correlação linear entre os dados de precipitação observada nas EMA e os dados dos conjuntos globais indica os maiores valores para a escala mensal, seguidos dos valores para as escalas pentadal e diária, nesta ordem. A precipitação observada na EMA de Presidente Prudente foi a que apresentou os maiores valores de correlação linear com os dados das fontes globais, nas três escalas temporais consideradas, diária, pentadal e mensal, seguida pela estação de Joaquim Távora e Paranaponema. GPCP e TRMM são os conjuntos de dados globais que apresentaram os maiores valores de correlação linear com os dados mensais das quatro estações automáticas consideradas. Por outro lado, o CHIRPS é o conjunto de dados de precipitação que melhor se ajusta linearmente aos dados diários das EMA. Para a análise pentadal, os conjuntos de dados globais do CHIRPS e GPCP, em relação aos dados do TRMM, se ajustam melhor aos dados de precipitação das estações automáticas. Para dados diários, os resultados de correlação com os dados do CHIRPS são os maiores, sobretudo para a EMA de Presidente Prudente $(r=0,53)$. Na escala pentadal, verificamos que os dados do TRMM e GPCP são relativamente bem correlacionados aos dados das EMA de Presidente Prudente e Paranaponema, apresentando valores significativos de correlação, superiores a 0,60. Na escala mensal, as três bases de dados globais utilizadas apresentaram valores significativos de correlação, superiores a 0,48 no caso das EMA de Ourinhos e Joaquim Távora. O ajuste linear entre a precipitação pentadal observada na EMA de Presidente Prudente e os dados dos conjuntos globais GPCP e TRMM, para o período considerado, apresenta $47 \%$ de explicação da variância da precipitação, isto significa dizer que, os conjuntos do GPCP e TRMM conseguem simular $47 \%$ da variância dos dados observados na EMA de Presidente Prudente. Para os dados mensais, os dados observados na EMA de Joaquim Távora se ajustam melhor aos dados do CHIRPS e TRMM (R2 = $55 \%$ ), enquanto que os dados mensais de Ourinhos apresentam o melhor ajuste linear quando as três bases de dados globais são consideradas ( $R 2=45 \%$ ). Com base nos resultados obtidos, sugere-se que os dados de fontes globais, por apresentarem constância temporal e espacial, podem ser usados em estudos sobre a variabilidade da precipitação em diversas escalas, em substituição aos dados diretamente observados nas estações automáticas. Contudo, sugere-se que anteriormente a qualquer estudo, seja realizada uma análise de consistência dos dados observados para a área de interesse. Embora sejam identificadas muitas semelhanças entre os conjuntos de dados considerados, as diferenças indicam que é necessário aprofundar o entendimento sobre suas causas, de forma a definir com mais precisão os limites de uso de dados oriundos das diversas fontes. 


\section{AGRADECIMENTOS}

O primeiro autor (Carlos Batista Silva) agradece o suporte financeiro efetuado pela CAPES. Tércio Ambrizzi agradece o suporte do CNPq e FAPESP. Natália Nunes Patucci agradece o financiamento da FAPESP referente ao projeto no 2016/06654-0.

\section{REFERÊNCIAS}

ADLER, Robert F. et al. The version-2 global precipitation climatology project (GPCP) monthly precipitation analysis (1979-present). Journal of hydrometeorology, v. 4, n. 6, p. 1147-1167, 2003.

ARKIN, Phillip A.; XIE, Pingping. The global precipitation climatology project: first algorithm intercomparison project. Bulletin of the American Meteorological Society, v. 75, n. 3, p. 401-419, 1994.

BECKER, A., FINGER, P., MEYER-CHRISTOFFER, A., RUDOLF, B., \& ZIESE, M. (2011). GPCC full data reanalysis version 7.0 at 0.5 : Monthly land-surface precipitation from raingauges built on GTS-based and historic data.

BROMWICH, D. H., FOGT, R. L., HODGES, K. I., \& WALSH, J. E. (2007). A tropospheric assessment of the ERA-40, NCEP, and JRA-25 global reanalyses in the polar regions. Journal of Geophysical Research: Atmospheres, 112(D10).

CHOU S.C. 1990. Análise de distúrbios ondulatórios de leste sobre o oceano Atlântico Equatorial Sul. INPE - 5222 - TDL / 437. (Dissert. Mestr.).

CONTI, José Bueno. Circulação secundária e efeito orográfico na gênese das chuvas na região lesnordeste paulista. Universidade de São Paulo, Instituto de Geografia, 1975.

CUNHA, Davi Gasparini; VECCHIA, Francisco. As abordagens clássica e dinâmica de clima: uma revisão bibliográfica aplicada ao tema da compreensão da realidade climática. Ciência e Natura, v. 29, n. 1, 2007.

DYER, T. G. J. Rainfall along the east coast of southern Africa, the Southern Oscillation, and the latitude of the subtropical high pressure belt. Quarterly Journal of the Royal Meteorological Society, v. 105, n. 444, p. 445-451, 1979.

FUNK, Chris et al. The climate hazards infrared precipitation with stations-a new environmental record for monitoring extremes. Scientific data, v. 2, 2015.

GAN M. A.; KOUSKY, V.E. Vórtices ciclônicos da alta troposfera no oceano Atlântico Sul. Revista Brasileira de Meteorologia, v. 1, 19-28, 1986.

HARRIS, I., JONES, P.D., OSBORN, T.J. AND LISTER, D.H. (2013), Updated high-resolution grids of monthly climatic observations - the CRU TS3.10 Dataset. Int. J. Climatol.. doi: 10.1002/joc.3711

HOREL, John D.; WALLACE, John M. Planetary-scale atmospheric phenomena associated with the Southern Oscillation. Monthly Weather Review, v. 109, n. 4, p. 813-829, 1981.

HOSKINS, Brian J.; KAROLY, David J. The steady linear response of a spherical atmosphere to thermal and orographic forcing. Journal of the Atmospheric Sciences, v. 38, n. 6, p. 1179-1196, 1981. 
INMET (Instituto Nacional de Meteorologia). < acessar referências em: http://www.inmet.gov.br/portal/css/content/topo_iframe/pdf/Nota_TecnicaRede_estacoes_INMET.pdf >, acessado em 03/02/2017.

JOLLIFFE, I.T. Principal Component Analysis, Series: Springer Series in Statistics, 2nd ed., Springer, NY, 2002, XXIX, 487 p. 28 illus.

KODAMA, Y.-M. Large-scale common features of subtropical precipitation zones (the Baiu frontal zone, the SPCZ, and the SACZ). Part I: Characteristics of subtropical frontal zones. J. Meteor. Soc. Japan, v. 70, p. 813-836, 1992.

KOUSKY, Vernon E. Frontal influences on northeast Brazil. Monthly Weather Review, v. 107, n. 9, p. 1140-1153, 1979.

LIMBERGER, Leila; SILVA, Maria Elisa Siqueira. Precipitação observada na Amazônia Brasileira: Redes convencionais e dados da Reanálise I do NCEP/NCAR, CRU e GPCC. Revista Brasileira de Climatologia, v. 22, 2018.

MONTEIRO, Carlos Augusto de Figueiredo. Frente polar atlântica e as chuvas de inverno na fachada sul-oriental do Brasil. In: Frente polar atlântica e as chuvas de inverno na fachada sul-oriental do Brasil. USP/IG, 1969.

MORIZE, H. Contribuição ao estudo do clima do Brasil. Rio de Janeiro: Ministério da Agricultura, 1922. 116 p.

PIKE, Arthur C. Intertropical convergence zone studied with an interacting atmosphere and ocean model. Mon. Wea. Rev, v. 99, p. 469-477, 1971.

REBOITA, Michelle Simões; GAN, Manoel Alonso; ROCHA, Rosmeri Porfírio da and AMBRIZZI, Tércio. Regimes de precipitação na América do Sul: uma revisão bibliográfica. Rev. bras. meteorol. [online]. 2010, vol.25, n.2 [cited 2018-07-12], pp.185-204. Available

<http://www.scielo.br/scielo.php?script=sci_arttext\&pid=S0102-

$77862010000200004 \&$ lng $=$ en\&nrm $=$ iso $>$. ISSN

http://dx.doi.org/10.1590/S0102-77862010000200004

RIEHL, Herbert. Waves in the easterlies and the polar front in the tropics. University of Chicago Press, 1945.

ROGERS, Jeffery C.; VAN LOON, Harry. Spatial variability of sea level pressure and $500 \mathrm{mb}$ height anomalies over the Southern Hemisphere. Monthly Weather Review, v. 110, n. 10, p. 1375-1392, 1982.

SALVIANO, Marcos Figueiredo; GROPPO, Juliano Daniel; PELLEGRINO, Giampaolo Queiroz. Análise de tendências em dados de precipitação e temperatura no Brasil. Revista Brasileira de Meteorologia, v. 31, n. 1, p. 64-73, 2016.

SIMPSON, Joanne; ADLER, Robert F.; NORTH, Gerald R. A proposed tropical rainfall measuring mission (TRMM) satellite. Bulletin of the American meteorological Society, v. 69, n. 3, p. 278-295, 1988.

SIMPSON, Joanne et al. On the tropical rainfall measuring mission (TRMM). Meteorology and Atmospheric physics, v. 60, n. 1-3, p. 19-36, 1996.

TALJAARD, J. J. Development, distribution and movement of cyclones and anticyclones in the Southern Hemisphere during the IGY. Journal of Applied Meteorology, v. 6, n. 6, p. 973-987, 1967. 
TROUP, A. J. The 'southern oscillation'. Quarterly Journal of the Royal Meteorological Society, v. 91, n. 390, p. 490-506, 1965.

WILKS, D.S. Statistical Methods in the Atmospheric Sciences: an introduction. San Diego. Academic Press. 467 p. 1995. 